\title{
The COVID-19 vaccine and the
} dental team

\section{James Dawson}

British Dental Association

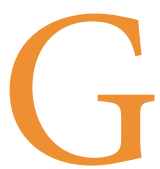

eneral immunity for practice staff will offer a much safer environment for providing dental services, reassuring patients and the dental team. With a number of vaccines having been developed and the NHS vaccination programme rolling out successfully there is much room for optimism. A vaccinated team is important. However, immunisations are voluntary and some may voice reluctance. The main point here is to look at the science and reassure your team.

Independent academic guidance co-ordinated by the University of Bristol provides in depth analysis of the development of the vaccines, their efficacy, effectiveness and safety. Their report is comprehensive, covering all aspects of the issue. ${ }^{1}$ It highlights the scientific facts and sorts out the myths and fallacies. You may find it indispensable in discussing vaccinations within your team.

\section{Employment law}

Vaccinations are generally not a contractual commitment. Employment contracts may require staff to be immunised when a new employee starts employment. Indeed this is the case for such infections as Hepatitis-B. But as of yet, this is not been recommended for new employees as regards COVID-19 vaccines. As the prevalence of the pandemic responds to the vaccination programme it might be that such a term is not needed. This will be reviewed in due course. In any case, such a term cannot be imposed on an existing employee without their agreement.

\section{Health and safety}

Health and safety rules mean employers have a general health and safety duty to their staff; and so should encourage staff to be vaccinated. Employees also have a health and safety obligation, for their own health and towards that of their colleagues, and vaccination would be a major way of ensuring that these duties are discharged.

\section{Professional obligations}

Dentalcare workers, especially those requiring registration with the GDC, must consider their professional obligations.

The General Dental Council, itself, has so far stated that it is not seeing COVID19 vaccination as mandatory. Though, this stance is somewhat out of line with requirements over Hepatitis- $\mathrm{B}$, so it is foreseeable that it may, in due course, change. The basis for this could be the interpretation of the GDC Standards for the Dental Team, Principle 1 'Put patients' interests first':

$\rightarrow 1.5$ : You must treat patients in a hygienic and safe environment

$\rightarrow$ 1.5.2: You must make sure that you have all necessary vaccinations and follow guidance relating to blood-borne viruses. ${ }^{2}$

With guidance that has been adopted UK-wide, Public Health England also provides crucial direction for the profession. Its publication Immunisation Against Infectious Disease (the Green Book), at Chapter 12 on Immunisation of healthcare and laboratory staff states:

$\rightarrow$ Any vaccine-preventable disease that is transmissible from person to person poses a risk to both healthcare professionals and their patients. Healthcare workers have a duty of care towards their patients which includes taking reasonable precautions to protect them from communicable diseases. Immunisation of healthcare and laboratory workers may therefore:

$\rightarrow$ Protect the individual and their family from an occupationally-acquired infection

$\rightarrow$ Protect patients and service users, including vulnerable patients who may not respond well to their own immunisation

$\rightarrow$ Protect other healthcare and laboratory staff

\begin{abstract}
$\rightarrow$ Allow for the efficient running of services without disruption. $^{3}$
\end{abstract}

\section{Reassurance and discussion}

Employers should, therefore, seek to persuade (but not force) their team members to take up COVID-19 vaccination. In this discussion, it is suggested that you all:

$\rightarrow$ Talk about the risks of infection and consequences of infection

$\rightarrow$ Talk about the advantages, efficacy and risks of the immunisation

$\rightarrow$ Ask team members if they have any concerns about immunisation; seek to evaluate and assess those concerns

$\rightarrow$ Consider any special circumstances. Vaccination is best. However, if having discussed the issues, a member of the dental team does not want to receive immunisation against COVID-19 then the practice and team member must both be satisfied that:

$\rightarrow$ The dentalcare worker has an objective reason for not being vaccinated, if this relates to a medical condition or a contraindication this should be supported by medical evidence

$\rightarrow$ There are appropriate alternative crossinfection control procedures in place, and

$\rightarrow$ That the dentalcare worker is adequately discharging their responsibilities to prevent the foreseeable risk of the employee transmitting the infection to colleagues or patients.

\section{References}

1. Lewandowsky S, Cook J, Schmid P, et al. COVID-19 Vaccine Communication Handbook. A practical guide for improving vaccine communication and fighting misinformation. Available at: https://sks.to/c19vax (Accessed February 2021).

2. General Dental Council. Standards for the Dental Team. Online at: https://standards.gdc-uk. org/Assets/pdf/Standards\%20for\%20the $\% 20$ Dental\%20Team.pdf (Accessed February 2021).

3. Department of Health. Immunisation Against Infectious Disease. Available at: https://assets. publishing.service.gov.uk/government/uploads/ system/uploads/attachment_data/file/147882/ Green-Book-Chapter-12.pdf (Accessed February 2021).

https://doi.org/10.1038/s41404-021-0676-9 